\title{
Reproducing the dopamine pathophysiology of schizophrenia and approaches to ameliorate it: a translational imaging study with ketamine
}

\author{
Michelle Kokkinou ${ }^{1,2}$ Elaine E. Irvine ${ }^{1,2} \cdot$ David R. Bonsall $^{3} \cdot$ Sridhar Natesan $\mathbb{D}^{4} \cdot$ Lisa A. Wells ${ }^{3} \cdot$ Mark Smith $^{1,2}$.

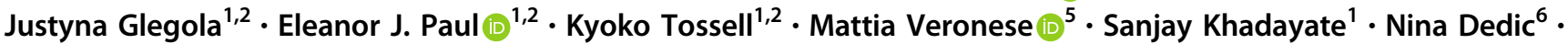 \\ Seth C. Hopkins ${ }^{6} \cdot$ Mark A. Ungless $^{1,2} \cdot$ Dominic J. Withers $^{1,2} \cdot$ Oliver D. Howes $^{1,2,4}$
}

Received: 1 July 2019 / Revised: 6 April 2020 / Accepted: 17 April 2020 / Published online: 7 May 2020

(c) The Author(s) 2020. This article is published with open access

\begin{abstract}
Patients with schizophrenia show increased striatal dopamine synthesis capacity in imaging studies. The mechanism underlying this is unclear but may be due to N-methyl-D-aspartate receptor (NMDAR) hypofunction and parvalbumin (PV) neuronal dysfunction leading to disinhibition of mesostriatal dopamine neurons. Here, we develop a translational mouse model of the dopamine pathophysiology seen in schizophrenia and test approaches to reverse the dopamine changes. Mice were treated with sub-chronic ketamine $(30 \mathrm{mg} / \mathrm{kg})$ or saline and then received in vivo positron emission tomography of striatal dopamine synthesis capacity, analogous to measures used in patients. Locomotor activity was measured using the open-field test. In vivo cell-type-specific chemogenetic approaches and pharmacological interventions were used to manipulate neuronal excitability. Immunohistochemistry and RNA sequencing were used to investigate molecular mechanisms. Sub-chronic ketamine increased striatal dopamine synthesis capacity (Cohen's $d=2.5$ ) and locomotor activity. These effects were countered by inhibition of midbrain dopamine neurons, and by activation of PV interneurons in prelimbic cortex and ventral subiculum of the hippocampus. Sub-chronic ketamine reduced PV expression in these cortical and hippocampal regions. Pharmacological intervention with SEP-363856, a novel psychotropic agent with agonism at trace amine receptor 1 (TAAR1) and 5- $\mathrm{HT}_{1 \mathrm{~A}}$ receptors but no appreciable action at dopamine $\mathrm{D}_{2}$ receptors, significantly reduced the ketamine-induced increase in dopamine synthesis capacity. These results show that sub-chronic ketamine treatment in mice mimics the dopaminergic alterations in patients with psychosis, that this requires activation of midbrain dopamine neurons, and can be ameliorated by activating PV interneurons and by a TAAR1/5-HT $1 \mathrm{~A}$ agonist. This identifies novel therapeutic approaches for targeting presynaptic dopamine dysfunction in patients with schizophrenia and effects of ketamine relevant to its therapeutic use for treating major depression.
\end{abstract}

\section{Introduction}

Supplementary information The online version of this article (https:// doi.org/10.1038/s41380-020-0740-6) contains supplementary material, which is available to authorised users.

$\square$ Dominic J. Withers

d.withers@imperial.ac.uk

$\triangle$ Oliver D. Howes

oliver.howes@1ms.mrc.ac.uk

1 MRC London Institute of Medical Sciences (LMS), London W12 0NN, UK

2 Institute of Clinical Sciences (ICS), Faculty of Medicine, Imperial College London, London W12 0NN, UK
Schizophrenia is a severe mental disorder and a significant global health burden, highlighting the need to better understand its neurobiology in order to develop improved

3 Invicro, Burlington Danes, Hammersmith Hospital, London W12 0NN, UK

4 Department of Psychosis Studies, Institute of Psychiatry, Psychology and Neuroscience, Kings College London, London, UK

5 Department of Neuroimaging, Institute of Psychiatry, Psychology and Neuroscience, Kings College London, London, UK

6 Sunovion Pharmaceuticals, 84 Waterford Drive, Marlborough, MA 01752, USA 
treatments [1]. Dopaminergic hyperactivity in the striatum is thought to underlie the symptoms of schizophrenia, particularly psychosis [2-5]. Supporting this, 3,4-dihydroxy-6- ${ }^{18} \mathrm{~F}$-fluoro-l-phenylalanine ( $\left[{ }^{18} \mathrm{~F}\right]$-FDOPA) positron emission tomography (PET) imaging studies have revealed higher striatal dopamine synthesis capacity in patients with schizophrenia [6-9]. Furthermore, increased dopamine synthesis capacity is associated with both the development of psychosis [10] and the severity of symptoms [11]. Currently available antipsychotics are all dopamine receptor blockers, which are inadequate and poorly tolerated in many patients, and do not address the mechanism underlying the dopamine dysfunction $[12,13]$. In addition to dopaminergic dysfunction, the glutamate hypothesis of schizophrenia has developed from the observations that $\mathrm{N}$-methyl-D-aspartate receptor (NMDAR) antagonists such as ketamine induce psychotic symptoms in healthy humans and exacerbate symptoms in patients $[14,15]$. Furthermore, schizophrenia is associated with a reduction in parvalbumin (PV)-expressing GABAergic interneurons, which are regulated by NMDARs in the cortex and hippocampus [16-18]. It has been suggested that impaired PV neuronal function in the cortex and hippocampus may lead to disinhibition of mesostriatal dopamine neuron activity via a polysynaptic pathway [19]. However, it is not clear if it is possible to develop a pre-clinical model of the increased dopamine synthesis capacity seen in patients using an NMDAR antagonist, and whether it is possible to reverse this by targeting $\mathrm{PV}$-expressing interneurons or other mechanisms.

To address this, we tested the effect of sub-chronic ketamine administration on dopamine synthesis capacity in mice using the same $\left[{ }^{18} \mathrm{~F}\right]$-FDOPA PET imaging technique that previously demonstrated elevation in dopamine synthesis capacity in patients [6-9], and also tested the potential of activating PV-interneurons to reverse the effects of ketamine on striatal dopamine synthesis capacity. We also tested the translational potential of a novel psychotropic agent, SEP-0363856 (SEP-856), to reverse striatal dopaminergic alterations based on evidence that it inhibits ventral tegmental area (VTA) neuronal firing [20]. Our objective was to develop a chemogenetics/PET approach that is translationally relevant and provides novel insights into the pathophysiology of schizophrenia.

\section{Methods and materials}

All experiments were approved by the UK Home Office under the Animal (Scientific Procedures) Act (ASPA) 1986 and Regulation 7 of the Genetically Modified Organisms (Contained Use) Regulations 2000. All procedures were performed in accordance with the ASPA 1986 and EU directive 2010/63/EU as well as being approved by Imperial College Animal Welfare and Ethical Review Body.

\section{Subjects}

Male mice were 6-8 weeks of age at the time of stereotaxic surgeries and 8-10 weeks of age at the start of the experiments. C57BL/6 wild-type, dopamine transporter (DAT) Cre (DAT::Cre) and parvalbumin (PV) Cre $(P V:: C r e)$ mice maintained on a C57BL/6 background were used.

\section{Sub-chronic ketamine regime}

Ketamine hydrochloride solid (Sigma-Aldrich) was dissolved in $0.9 \%$ saline solution to $6 \mathrm{mg} / \mathrm{ml}$ and injected at a volume of $5 \mathrm{ml} / \mathrm{kg}$ of body weight, thus administered at a dose of $30 \mathrm{mg} /$ $\mathrm{kg}$ (i.p) once daily for 5 consecutive days (Fig. 1a, Supplementary Figs. 1a, 2a, 3a, 4) [21]. Control mice received an equivalent volume of $0.9 \%$ saline vehicle.

\section{Chemogenetics model}

In DAT::Cre mice adeno-associated virus (AAV) vectors were stereortaxically targeted to the ventral tegmental area (VTA: anteroposterior [AP] $-3.15 \mathrm{~mm}$, mediolateral [ML] $\pm 0.40 \mathrm{~mm}$, dorsoventral [DV] $-4.30 \mathrm{~mm}$ ) and the substantia nigra pars compacta (SNc: AP $-3.15 \mathrm{~mm}$, ML $\pm 1.50 \mathrm{~mm}$, DV $-4.30 \mathrm{~mm}$ ) (Fig. 2b). In PV::Cre mice viruses were stereotaxically injected in pre-limbic cortex (PLc: AP +1.94, ML $\pm 0.45, \mathrm{DV}-2.20$ ) and in the ventral subiculum (vSub) of the hippocampus (vSub: AP -3.20 , ML \pm 2.80 , DV -4.30 ) (Figs. 3a, 4b, Supplementary Fig. 5). Both the PLc and vSub regions were targeted concurrently for the following reasons. In schizophrenia there are deficits in PV interneuron markers in both the prefrontal cortex and in the hippocampus [16, 22-25]. In addition, acute and chronic ketamine administration is associated with deficits in PV interneuron markers in both regions [16, 17, 26-29]. The needle was left in place for 3 min post injection. Following injections, the wound was sutured (Mersilk, 3-1 Ethicon). Two weeks following the surgeries, clozapine Noxide (CNO) $(0.1$ and $0.5 \mathrm{mg} / \mathrm{kg}$, i.p) or saline was administered $30 \mathrm{~min}$ before the injection of ketamine or saline (Figs. 2a, 4a). See Supplementary Methods for further details.

\section{Open-field test}

Mice were placed into the open-field arena for a $20 \mathrm{~min}$ habituation period, then injected i.p with either ketamine or saline and placed back in the arena for a further $60 \mathrm{~min}$. Total distance travelled was recorded using the Ethovision 
a

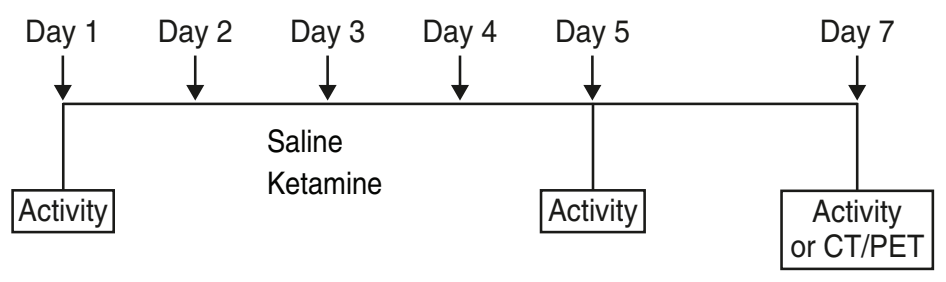

b

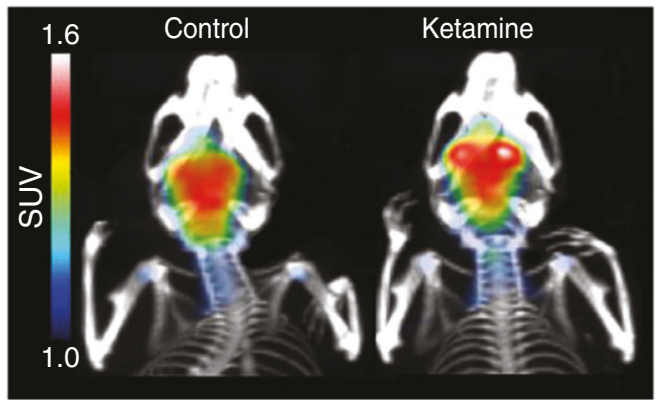

d

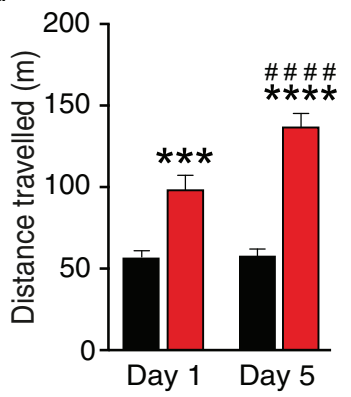

e

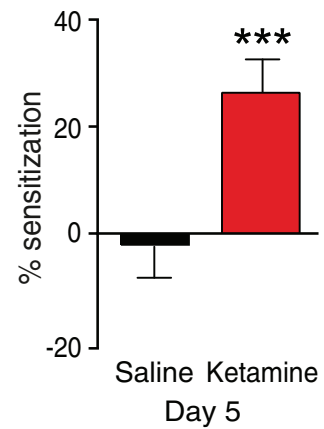

c

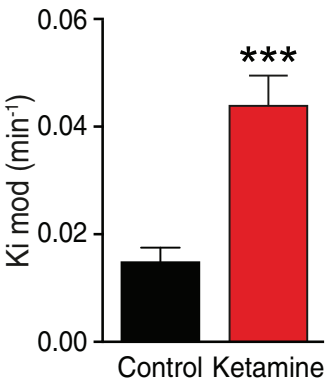

f

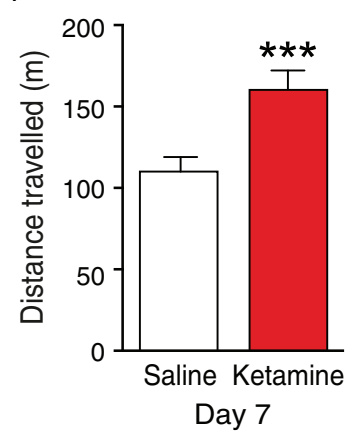

Fig. 1 Sub-chronic ketamine increases dopamine synthesis capacity and locomotor activity. a Schematic showing the drug treatment schedule used to study the effect of sub-chronic ketamine administration on striatal dopamine synthesis capacity and locomotor activity in the mouse. $\mathbf{b}\left[{ }^{18} \mathrm{~F}\right]$-FDOPA PET brain image coregistered to a computed tomography (CT) scan demonstrating high signal to noise ratio in striatal uptake from representative mice treated with saline or ketamine, and showing increased uptake in ketamine-treated mice. Standardised uptake value (SUV) is presented as summed activity over the timeframe (20-90 min) used to measure dopamine synthesis capacity. c Striatal dopamine synthesis capacity $\left(K_{\mathrm{i}}^{\text {mod }} / \mathrm{min}\right)$ is significantly increased in the ketamine-treated $(n=8)$ group versus control $(n=7)$ group $(* * * P<$ 0.001, two-tailed, Cohen's $\left.d=2.5, t_{13}=4.74\right)$. d Total distance

XT video tracking software system (Noldus Information Technologies, Leesburg, VA, USA). Locomotor activity was assessed on days 1,5 and 7 of drug treatment (Supplementary Fig. 1). For the chemogenetic experiments, mice were placed in the open-field arenas for $20 \mathrm{~min}$ habituation, they then received an injection of $\mathrm{CNO}$ or saline and activity was recorded for $30 \mathrm{~min}$. Then, mice received an injection of ketamine or saline, in line with the treatment schedule, and their activity recorded for $60 \mathrm{~min}$. Locomotor activity was assessed on days 1 and 5 of drug treatment (Supplementary Figs. 2-4). travelled during $30 \mathrm{~min}$ post drug administration. There was a significant effect of group $\left(F_{(1,26)}=46.21, P<0.0001\right)$, day $\left(F_{(1,26)}=\right.$ 23.27, $P<0.0001)$ and group $\times$ time interaction $\left(F_{(1,26)}=20.79, P<\right.$ 0.001 ; Bonferroni post hoc (asterisks indicate $p$-values for saline vs ketamine on the same day; hash indicates $p$-values for day 1 vs day 5), showing that ketamine induces hyperlocomotion. e Sub-chronic ketamine induces locomotor sensitisation $(* * * P<0.001)$. f Locomotor sensitization is sustained following a 2-day washout of ketamine. Ketamine induced significantly higher locomotor activity in mice that had received sub-chronic ketamine as compared with mice that had received saline for 5 days $(* * * P<0.001)$. Data represent mean \pm S.E.M. **** $P<0.0001$; *** $P<0.001$; \#\#\#\# $P<0.0001$. PET positron emission tomography, CT computed tomography.

\section{Positron emission tomography (PET) imaging}

One hour prior to scanning, mice were anaesthetised with isoflurane and underwent external jugular vein cannulation. During scanning, the respiration rate was monitored using the BioVet physiological monitoring software system (Biovet software; m2m Imaging Corp, Cleveland, $\mathrm{OH}$, USA) and body temperature was maintained at $37^{\circ} \mathrm{C}$. Mice received $40 \mathrm{mg} / \mathrm{kg}$ (i.p) entacapone (SML0654, SigmaAldrich), a catechol-O-methyl-transferase inhibitor, and 10 $\mathrm{mg} / \mathrm{kg}$ (i.p) benserazide hydrochloride (B7283, Sigma- 
a

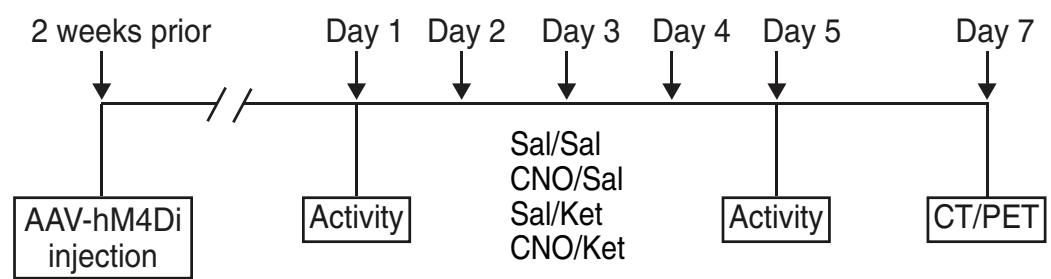

b

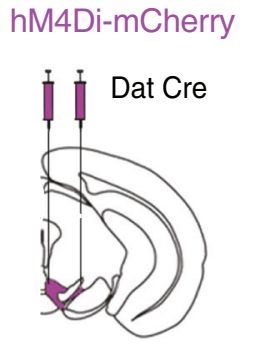

$\mathrm{VTA} \pm 0.40 \mathrm{SNc} \pm 1.50$

e

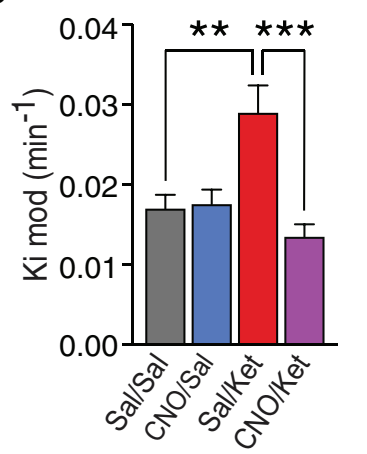

f

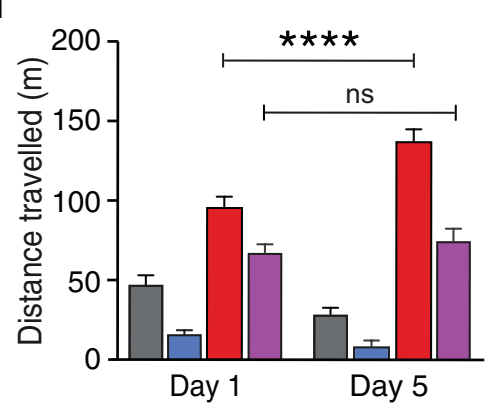

d

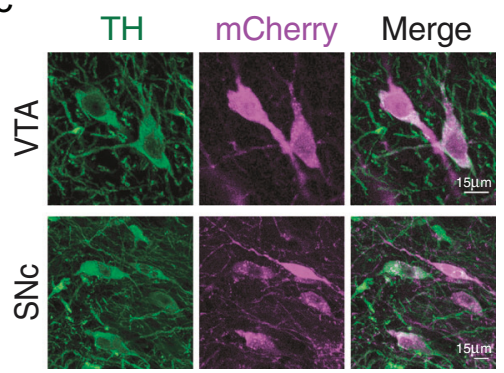

Fig. 2 Midbrain dopamine neuron firing is necessary for ketamine-induced increases in dopamine synthesis capacity and locomotor activity. a Experimental timeline and drug treatment paradigm used to assess the effect of midbrain dopamine neuron inhibition on the sub-chronic ketamine-induced increase in striatal dopamine synthesis capacity and locomotor activity. Two weeks after stereotaxic injection of AAV-hM4Di-mCherry, mice received $0.1 \mathrm{mg} /$ $\mathrm{kg} \mathrm{CNO}$ or vehicle followed by ketamine $(30 \mathrm{mg} / \mathrm{kg}$ ) or vehicle $30 \mathrm{~min}$ later for 5 consecutive days. Mice underwent a dynamic PET/CT scan 2 days after the last drug administration. b Bilateral infusion of AAVhM4Di-mCherry into the VTA and SNc of DAT::Cre mice was used to selectively express DREADD receptors in dopamine neurons. c Fluorescence confocal images of representative midbrain fields depicting co-expression (white) of mCherry (magenta) and TH (green) immunofluorescence. d Percentage of $\mathrm{TH}+$ neurons co-expressing mCherry (47 out of total $65 \mathrm{TH}+$ neurons; $71.7 \pm 11 \%$ ) and percentage of mCherry+ which do not express TH (1 out of total 48 mCherry +

Aldrich), an aromatic amino acid decarboxylase inhibitor, at 45 and $30 \mathrm{~min}$ before the $\left[{ }^{18} \mathrm{~F}\right]$-FDOPA respectively. This improves brain uptake $\left[{ }^{18} \mathrm{~F}\right]$-FDOPA by reducing peripheral metabolism of the radiotracer [30]. SEP-363856 (3 mg/kg, i.p), a TAAR1/5HT 1 A agonist, was provided by Sunovion Pharmaceuticals and administered $30 \mathrm{~min}$ prior to the $\left[{ }^{18} \mathrm{~F}\right]-$ neurons, $1.5 \pm 1.5 \%$ ) in the VTA. Percentage of TH+ neurons coexpressing mCherry (47 out of total $52 \mathrm{TH}+$ neurons; $89.6 \% \pm 5.4$ ) and percentage of mCherry + which do not express $\mathrm{TH}$ ( 1 out of total 48 mCherry + neurons, $1.5 \pm 1.5 \%$ ) in the SNc. e Striatal dopamine synthesis capacity $\left(K_{\mathrm{i}}^{\text {mod }} / \mathrm{min}\right)$ is significantly reduced in $\mathrm{CNO} / \mathrm{Ket}$ compared with Sal/Ket group $(* * * P<0.001)(\mathrm{Sal} / \mathrm{Sal}(n=12), \mathrm{CNO} /$ Sal $(n=13)$, Sal/Ket $(n=12)$ and $\mathrm{CNO} / \operatorname{Ket}$-treated $(n=11)$ groups). f Total distance travelled during $30 \mathrm{~min}$ post drug administration. Subchronic ketamine treatment induced locomotor sensitization that was prevented by inhibition of midbrain dopamine neuron firing prior to ketamine treatment. g Percentage locomotor sensitization between day 1 and day 5. Data represent mean \pm S.E.M. $* * * * P<0.0001$; $* * * P<0.001 ; * * P<0.01 ; * P<0.05$. Sal saline, Ket ketamine, CNO clozapine N-oxide, TH tyrosine hydroxylase, PET positron emission tomography, CT computed tomography, VTA ventral tegmental area, $\mathrm{SNc}$ substantia nigra pas compacta.

FDOPA injection. Following cannulation, mice were transferred to the bore of an Inveon $\mu$ PET/CT scanner (Siemens, Surrey, UK). Mice underwent a 20 min CT scan for attenuation correction, and then received a bolus injection of $\sim 4.5 \mathrm{MBq}\left[{ }^{18} \mathrm{~F}\right]$-FDOPA via the external jugular vein cannula at the start of the 120 min dynamic PET scan. 
a
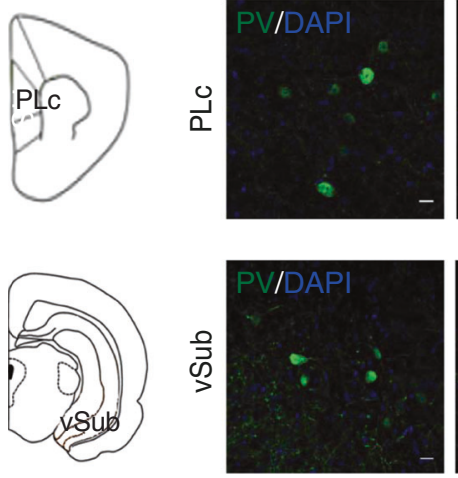

b

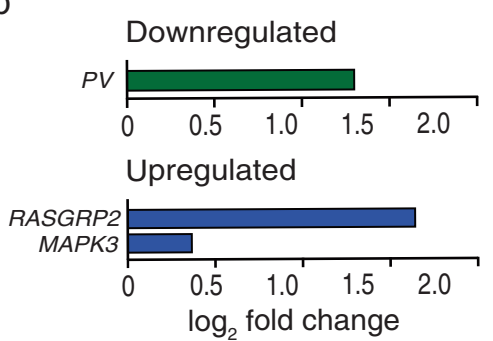

Fig. 3 Sub-chronic ketamine reduces parvalbumin interneuron function. a Schematics of the location of the PLc and vSub of the hippocampus in the brain. Representative fluorescence confocal images of PLc and vSub of the hippocampus fields respectively depicting PV interneuron (green) and DAPI (blue) immunofluorescence in saline-treated (Saline) and ketamine-treated (Ketamine) mice. PV immunofluorescence in the PLc and vSub of the hippocampus is significantly reduced in the ketamine versus saline group (Two-way repeated-measures ANOVA significant effect of treatment, $F_{1,8}=$

\section{PET analysis}

Inveon Research Workplace software (Siemens USA) was used to draw 3D regions of interest manually on summation radioactivity images at the level of the striatum (right and left) $\left(0.07 \mathrm{~cm}^{3}\right)$ and the cerebellum $\left(0.1 \mathrm{~cm}^{3}\right)$ to extract time activity curves (Supplementary Figs. 6, 7) [31]. Dopamine synthesis capacity was indexed as the rate constant for the uptake and conversion of $\left[{ }^{18} \mathrm{~F}\right]$-FDOPA to $\left[{ }^{18} \mathrm{~F}\right]$-dopamine, $K_{\mathrm{i}}^{\text {mod }}\left(\mathrm{min}^{-1}\right)$, and determined using a modified Patlak plot accounting for the loss of radioactive metabolites, $k_{\text {loss }}$ $[30,32]$. The cerebellum was used as the reference region, in line with the approach used in human studies, to account for non-specific uptake as it has negligible dopaminergic projections $[33,34]$.

\section{RNA sequencing (RNA Seq)}

Two days following 5 days of ketamine or saline injections, brains were rapidly removed and the PLc was dissected and frozen in isopentane on dry ice. Total RNA was isolated using the TriZol reagent (Invitrogen) and purified using
Ketamine
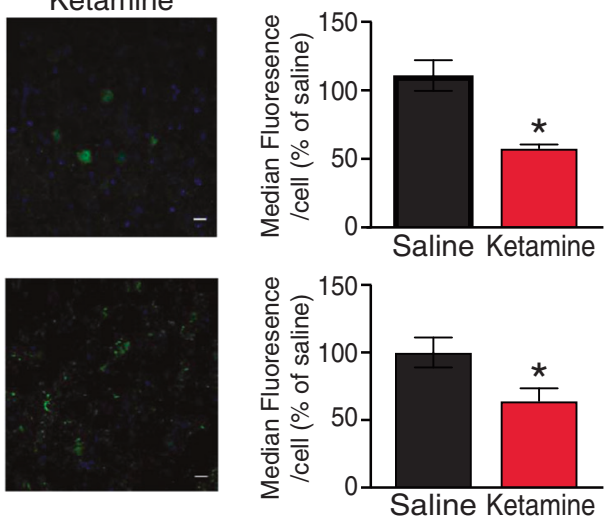

C

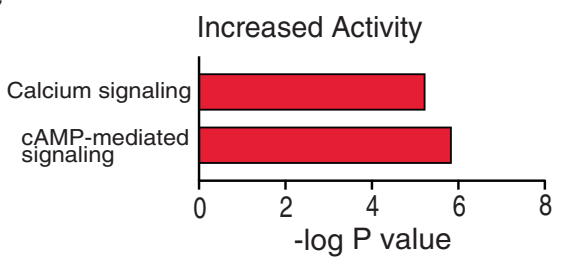

47.28, $p<0.001, \eta^{2}$ effect size $=0.86$; followed by Bonferroni post hoc tests $(P<0.05) ; n=5$ mice per group). b Differential expression of the PV gene in ketamine-treated mice vs. saline treated controls. Differential expression of RASGRP2 and MAPK3 genes in ketaminetreated mice vs. saline treated controls. $\log 2$ fold change is shown in each respective bar. $\mathbf{c}$ Increased activity in the calcium signalling and cAMP-mediated signalling pathways in ketamine-treated vs. control group. Data represent mean \pm S.E.M. $* P<0.05$. PLc pre-limbic cortex, vSub ventral subiculum of the hippocampus, PV parvalbumin.

RNAeasy micro kits from Qiagen. RNA integrity was assessed using the Agilent Bioanalyser and all RNA integrity number values were above 8 . Then, the cDNA library was prepared using the NEB Next Ultra II Library Prep kit (New England Biolabs, USA). Sequencing was conducted on an Illumina HiSeq 2500 system with 100 base pair paired-end reads (London, UK). Raw reads were aligned to $\mathrm{mm} 9$ genome using Tophat version (2.0.11) [35]. Gene based counting was performed using the HTSeq counts module. Gene expression analysis was performed using the DESeq2 Bioconductor package. All genes with adjusted $p$ value of 0.05 or less (calculated from the raw $p$ values using the Benjamini and Hochberg algorithm) were considered statistically significant. The RNA seq data are available at https://www.ncbi.nlm.nih.gov/geo/query/acc. cgi?acc $=\mathrm{GSE} 138802$.

\section{Statistical analysis}

Statistical analyses were performed using Prism 7.00 software (GraphPad Software, La Jolla, California, USA). Normality of distributions was assessed using the 
a

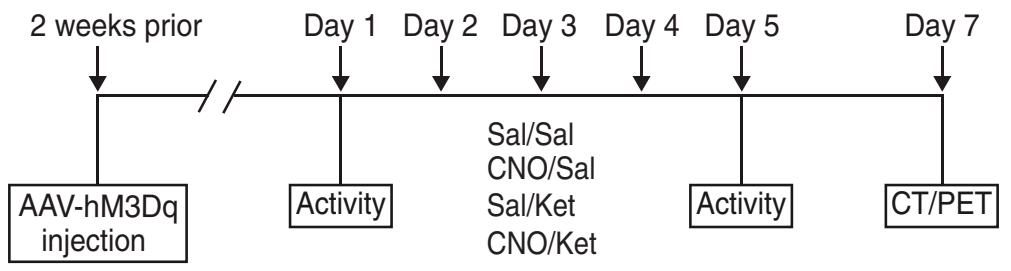

b

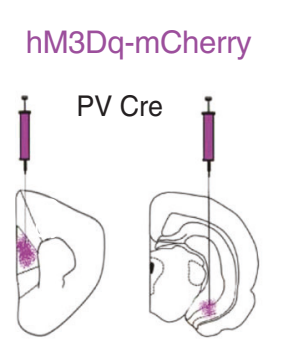

PLc +1.94 vSub -3.20
C

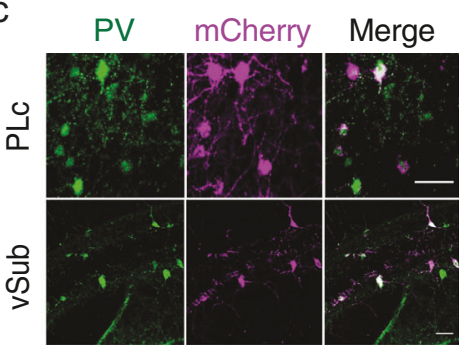

d

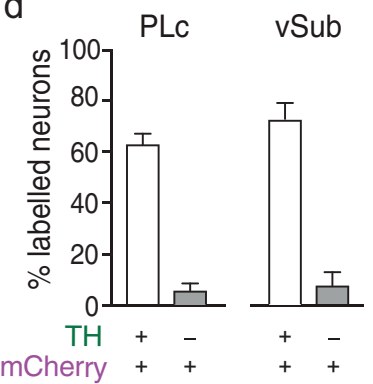

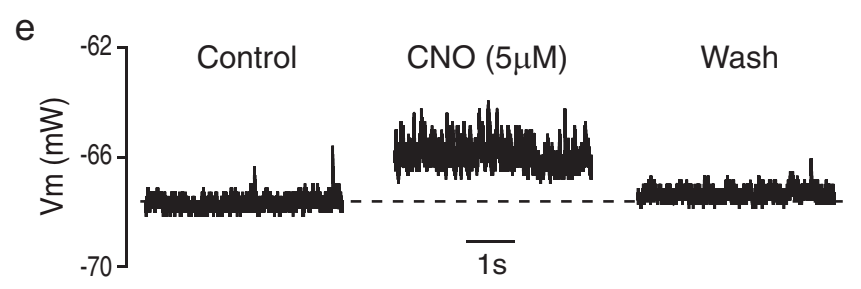

$f$

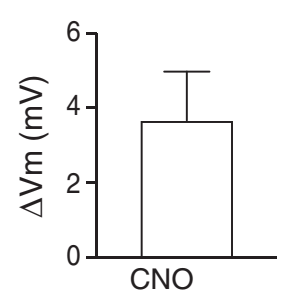

g

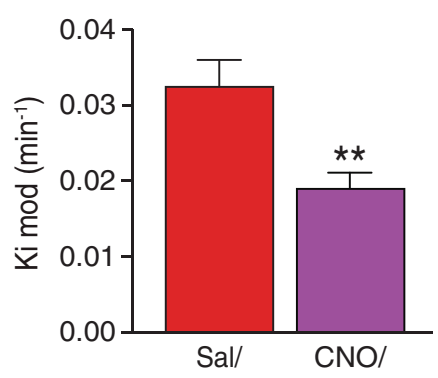

Fig. 4 In vivo parvalbumin interneuron activation attenuates the effects of sub-chronic ketamine-induced increase in dopamine synthesis capacity and locomotor activity. a Experimental timeline and drug treatment schedule used to study the effect of PV neuron activation on the sub-chronic ketamine-induced increase in striatal presynaptic dopamine synthesis capacity. Two weeks following stereotaxic injection of AAV-hM3Dq-mCherry, mice received $0.5 \mathrm{mg} / \mathrm{kg}$ $\mathrm{CNO}$ or vehicle, followed by ketamine $(30 \mathrm{mg} / \mathrm{kg})$ or vehicle treatment 30 min later for 5 consecutive days. Mice underwent a dynamic PET/ CT scan 2 days following the last drug administration. b Bilateral infusion of AAV-hM3Dq-mCherry into the PLc and vSub of $P V:$ Cre mice was used to selectively express DREADD receptors in PV interneurons. c Representative fluorescence confocal images of PLc and vSub fields depicting co-expression (white) of mCherry (magenta) and PV (green) immunofluorescence. d Percentage of PV+ neurons co-expressing mCherry (120 out of total $177 \mathrm{PV}+$ neurons; $65 \pm 4.4 \%$ ) and percentage of mCherry+ which do not express PV ( 9 out of total 129 mCherry + neurons, $5.8 \pm 2.9 \%$ ) in the PLc. Percentage of $\mathrm{PV}+$ neurons co-expressing mCherry (51 out of total $71 \mathrm{PV}+$ neurons; $72.9 \pm 6.3 \%$ ) and percentage of mCherry + which do not express PV (5 out of total 59 mCherry+ neurons, $7.8 \pm 5.2 \%$ ) in the vSub.

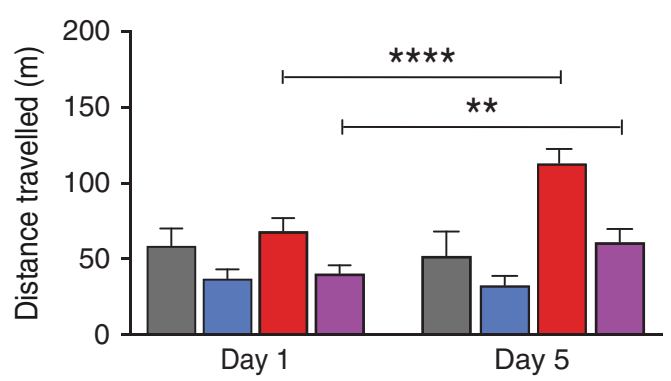

e Effect of 5 microM CNO on membrane potential measured in voltage clamp configuration from a whole-cell recording of PV interneuron within the vSub from a $P V:: C r e$ mouse injected with AAV-hM3DqmCherry. f Change in membrane potential with positive showing increase relative to the baseline indicative of $\mathrm{PV}$ neuron depolarisation upon CNO application. g Striatal dopamine synthesis capacity $\left(K_{\mathrm{i}}^{\text {mod } /}\right.$ $\mathrm{min})$ is significantly reduced in $\mathrm{CNO} /$ ketamine-treated $(n=11)$ (purple) versus SAL/Ket $(n=11)$ (red) group, unpaired t-test $(* * P<0.01$, $t_{19}=3.51$, two-tailed, effect size $\left.=1.59\right)$. $\mathbf{h}$ Total distance travelled during a $30 \mathrm{~min}$ test period post drug administration. Sub-chronic ketamine treatment induced locomotor sensitization, which was not prevented by activation of $\mathrm{PV}$ interneuron firing prior to ketamine treatment $\left(F_{1,44}=15.51\right.$, *** $P<0.001$, Bonferroni post hoc test $* * P<0.01 * * * P<0.001=$ day 1 vs. day 5 ). On day 5 activation of $\mathrm{PV}$ interneuron firing prevented the effects of sub-chronic ketamine on locomotor activity $\left(F_{3,44}=9.283, * * * P<0.001\right.$, Bonferroni post hoc test $* * * P<0.001 \mathrm{Sal} / \mathrm{Ket}$ vs. all other groups). Data represent mean \pm S.E.M. $* * * * P<0.001 ; * * P<0.01$. Sal saline, Ket ketamine, CNO clozapine N-oxide, PET positron emission tomography, CT computed tomography, PLc pre-limbic cortex, vSub ventral subiculum of the hippocampus, PV parvalbumin. 
Kolmogorov-Smirnov test and Levene's test for equality of variance to guide the choice of statistic. Between-group comparisons were made with two-tailed independent samples $t$ tests for normally distributed data, and Mann-Whitney $U$ tests were used for non-parametric data. Two-way analysis of variance (ANOVA) was used to test the difference in outcome measure between the four experimental groups. Locomotor sensitization was analysed with a two-way repeated-measures ANOVA, with the days as the repeated measure and experimental group as the cofactor. Outliers in the data were identified using the Grubbs's test. Post hoc comparisons were Bonferroni corrected. Cohen's $d$ effect sizes were calculated using the online calculator (http://www.uccs.edu/ lbecker/). Data are expressed as mean \pm s.e.m. and statistical significance was defined as $p<0.05$ (two tailed).

\section{Results}

\section{Sub-chronic ketamine increases dopamine synthesis capacity and locomotor activity}

To test the hypothesis that sub-chronic ketamine administration leads to increased dopamine synthesis capacity, mice were injected once daily with ketamine $(30 \mathrm{mg} / \mathrm{kg}$ ) or saline for 5 consecutive days. Two days after the last ketamine or saline injection in vivo $\left[{ }^{18} \mathrm{~F}\right]$-FDOPA PET imaging was performed. Sub-chronic ketamine treatment significantly increased striatal dopamine synthesis capacity compared to controls, with an effect size of $d=$ $2.5\left(P<0.001, t_{13}=4.74\right)$ (Fig. 1b, c, Supplementary Table 1). We also examined locomotor sensitization, which has been used as a behavioural model of the dopaminergic dysfunction seen in psychosis [36]. Acute ketamine administration (day 1) induced locomotor hyperactivity in the open-field test. Repeated ketamine administration (day 5) induced locomotor sensitization, an effect that was sustained following 2-day washout of ketamine (day 7) (Fig. 1d-f; Supplementary Fig. 1). Collectively, these findings indicate that sub-chronic ketamine administration induces both an increase in dopamine synthesis capacity and behavioural changes relevant to schizophrenia.

\section{Midbrain dopamine neuron firing is necessary for ketamine-induced increases in dopamine synthesis capacity and locomotor activity}

To test if the reported ketamine-induced firing activity of dopamine neurons [37-39] underlies the increase in dopamine synthesis capacity we observed, we employed a chemogenetic approach to selectively suppress dopamine neuron activity in vivo. We injected an adeno-associated virus (AAV) containing a Cre-dependent hM4Di-mCherry fusion protein (AAV1-DIO-hM4Di-mCherry) into the VTA and the substantia nigra pars compacta $(\mathrm{SNc})$ of $D A T:: C r e$ mice. Cre-dependent expression of $h M 4 D i$ $m$ Cherry showed $\sim 98 \%$ specificity for dopamine neurons, and CNO-treatment silenced dopamine neuron firing in slice electrophysiology recordings, consistent with our previous findings (Fig. 2b-d) [40]. Administration of $\mathrm{CNO}$ prior to ketamine dosing prevented the elevation in striatal dopamine synthesis capacity (Fig. 2e, Supplementary Table 2) and the ketamine-induced locomotor sensitization compared to the relevant control groups (Fig. 2f, g, Supplementary Fig. 2). It has recently been shown that clozapine, converted from $\mathrm{CNO}$, may have off-target effects at endogenous receptors rather than at the DREADDs exclusively [41]. Importantly, CNO administration in transgenic mice expressing a control construct had no effect on the ketamine-induced increase in dopamine synthesis capacity and locomotor activity (Supplementary Fig. 4), indicating that DREADDmediated silencing of dopaminergic neurons is responsible for the observed effects. Taken together, these findings suggest that sub-chronic ketamine increases dopamine synthesis capacity and locomotor sensitization through a mechanism that drives firing activity of midbrain dopamine neurons.

\section{The effect of sub-chronic ketamine on PV expression and function}

Lower levels of PV neurons in the cortex and hippocampus have been observed in schizophrenia patients and following acute ketamine treatment $[16,17,27,42]$. In addition, it is believed that reduced PV neuron function may lead to changes in dopamine neuron activity [19]. Therefore, we examined the effects of ketamine on various elements of PV interneuron function including PV expression. We found that sub-chronic ketamine treatment reduced PV interneuron immunofluorescence in the pre-limbic cortex (PLc) and the ventral subiculum (vSub) of the hippocampus $(P<$ $0.05, \eta^{2}$ effect size $=0.86$ ) relative to saline controls (Fig. 3a).

To investigate the molecular mechanisms underlying the effects of sub-chronic ketamine on dopamine synthesis we performed RNA Seq on PLc tissue. We hypothesised that sub-chronic ketamine would result in reduced PV expression, and changes in signalling pathways downstream of the NMDA receptor such as calcium signalling and the activation of brain-derived neurotrophic factor (BDNF) signalling. Consistent with our a priori hypotheses, RNA Seq data on PLc tissue revealed reductions in the expression of PV (Fig. 3b). Moreover, consistent with the hypothesis that 
blocking NMDAR activity increases BDNF signalling [43], we observed a significant increase in the expression of genes involved in the pathway downstream of BDNF signalling, specifically upregulation of mitogen-activated protein kinase 3 (MAPK3) and RAS guanyl releasing protein 2 (Rasgrp2) (Fig. 3b). In addition, cAMP-mediated signalling and calcium signalling pathways were significantly activated in ketamine vs. saline conditions (Fig. 3c). Furthermore, using Ingenuity-pathway analysis (IPA, QUIAGEN Redwood City, https://www.qiagenbioinformatics.com/ products/ingenuity-pathway-analysis/) L-DOPA was the significant upstream regulator of the differentially expressed genes in ketamine vs. saline conditions $(z$-score $=2.961$, $P<0.05$, in cortex). Collectively, these data support the hypothesis that sub-chronic ketamine increases dopamine synthesis capacity via a pathway that involves the inhibition of PV interneuron function. Furthermore, RNA Seq data on PLc tissue did not reveal changes in the expression of cholecystokinin $(p>0.05)$, nitric oxide synthase $1(p>0.05)$ and somatostatin $(p>0.05)$, which are proteins expressed in other GABAergic interneurons. Interestingly, consistent with a previous study, vasoactive intestinal peptide receptor 2 (VIPR2) expression was significantly increased suggesting that other GABAergic interneurons may be affected by sub-chronic ketamine administration.

\section{The role of PV interneuron activity in mediating the effects of sub-chronic ketamine}

Given that ketamine reduced PV expression levels, and the hypothesised role of PV interneuron hypofunction in schizophrenia [44, 45], we aimed to determine if activating PV interneurons in the PLc and vSub of the hippocampus was able to counter the ketamine-induced increase in dopamine synthesis capacity. To test this, AAVs expressing a Credependent $h M 3 D q$-mCherry fusion protein were stereotaxically injected into the PLc and vSub of the hippocampus of $P V:: C r e$ mice (Fig. 4a, b). Immunohistochemistry revealed co-localisation of mCherry with PV immunoreactive neurons and a successful transduction with over 92\% specificity in the PLc and vSub (Fig. 4c, d). In ex vivo slice electrophysiology studies, application of CNO depolarised vSub PV neurons expressing mCherry (Fig. 4e, f). Using this system, we found that in vivo activation of PV interneurons in the PLc and vSub, prior to ketamine administration, significantly reduced both the elevation in striatal dopamine synthesis capacity $\left(P<0.01, t_{19}=3.51\right.$, two-tailed, effect size $=1.59$ ) (Fig. 4g; Supplementary Table 3) and the locomotor effects of acute and sub-chronic ketamine (Fig. 4h; Supplementary Fig. 3). Therefore, our results suggest that ketamine increases dopamine synthesis capacity and locomotor activity via its actions on cortical/ hippocampal PV interneurons.

\section{A novel TAAR1/5-HT $1 \mathrm{~A}$ agonist counteracts the ketamine-induced increase in dopamine synthesis capacity}

Our findings suggest that targeting dopamine neuron firing activity may present a viable therapeutic target for the increase in dopamine synthesis capacity seen in schizophrenia. One potential candidate mechanism is trace amine receptor 1 (TAAR1) agonism. TAAR1 is a G-proteincoupled receptor that is expressed throughout monoaminergic brain nuclei including dopamine neurons [46]. TAAR1 agonists have been shown to reduce dopamine firing rates and release [47-49]. In view of this, we tested whether SEP-0363856 (SEP-856), a novel psychotropic agent with agonism at TAAR1 and $5 \mathrm{HT}_{1 \mathrm{~A}}$ receptors [20], counteracts the effect of sub-chronic ketamine treatment on dopamine synthesis capacity. Ketamine-treated mice that received SEP-856 (3 mg/kg, i.p) showed significantly lower striatal dopamine synthesis capacity compared to vehicle controls $\left(P<0.05, t_{29}=2.839\right)$ (Fig. 5). Post hoc analyses showed that $K_{\mathrm{i}}^{\text {mod }}$ in ketamine-treated mice that received SEP-856 was not significantly different from $K_{\mathrm{i}}^{\text {mod }}$ in mice not exposed to ketamine (Fig. 5).

\section{Discussion}

Our results demonstrate that sub-chronic ketamine administration leads to elevated striatal dopamine synthesis capacity, and that this requires the activation of midbrain dopamine neurons. The ketamine-induced increase in

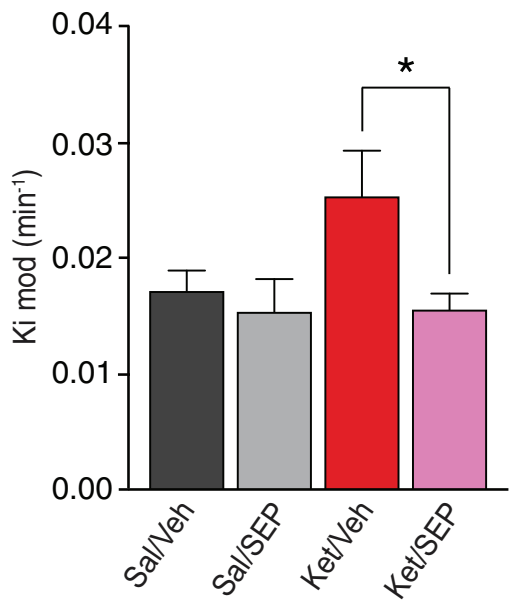

Fig. 5 The novel trace amine receptor 1 agonist SEP-0363856 (SEP-856) attenuates the ketamine-induced increase in dopamine synthesis capacity. Striatal dopamine synthesis capacity $\left(K_{\mathrm{i}}^{\text {mod }} / \mathrm{min}\right)$ was significantly reduced in the ketamine model following the administration of SEP compared with vehicle in the ketamine model. $\mathrm{Ket} / \mathrm{SEP}(n=9)$ (Magenta) versus Ket/Veh $(n=8)($ red $) * P<0.05$. Sal saline, Ket ketamine, Veh vehicle, SEP SEP-0363856. 
dopamine synthesis capacity was attenuated by the activation of PV interneurons in the PLc and vSub, as well as by a novel TAAR1/5HT $1 \mathrm{~A}$ agonist, SEP-856. Our study demonstrates for the first time to our knowledge that an experimental model induces the same dopaminergic phenotype seen in patients with psychosis, and the potential of targeting PV interneurons and a novel TAAR1/5HT $1 \mathrm{~A}$ agonist to reverse the dopaminergic phenotype.

The majority of studies show that acute ketamine significantly increases striatal dopamine levels [50-53], and elevates VTA dopamine neuron firing [38, 39, 54]. Our results extend these findings to show that sub-chronic ketamine induces a persistent elevation of dopamine synthesis capacity through a mechanism that requires midbrain dopamine neuron firing. These results are in line with the increased striatal dopamine synthesis capacity observed in schizophrenia patients and were acquired using an equivalent PET imaging technique. It should be noted that we investigated dopamine synthesis capacity in the striatum and, although it includes nucleus accumbens, most of the signal is from dorsal regions (caudate and putamen) [34]. Therefore, inferences about the dopamine system elsewhere (e.g. in cortical regions) cannot be made. In addition, we extend prior findings of reductions in PV levels in the hippocampus and prefrontal cortex following acute or subchronic ketamine administration [27, 42], to show that ketamine also leads to persistent reductions in PV levels and that activation of PV interneurons can attenuate ketamineinduced increases in striatal dopamine synthesis capacity.

\section{Proposed mechanism of action of ketamine on dopamine synthesis capacity}

Ketamine is a non-competitive NMDAR antagonist that binds with high affinity $(\mathrm{Ki}=3.1 \mu \mathrm{M})$ to the same binding site as MK801 and PCP [55-57]. PV interneurons are activated upon glutamate binding to NMDAR, and subsequently inhibit the activity of cortical pyramidal neurons [58-60]. Therefore, by blocking NMDARs, ketamine is thought to reduce the activity of PV interneurons and thereby disinhibit cortical pyramidal neurons, including neurons that project to subcortical regions to ultimately disinhibit midbrain dopamine neuron firing $[19,38$, 6163]. In line with this model of the mechanism of action of ketamine on the dopaminergic system, ketamine has been associated with a reduction in PV interneuron function, excessive glutamate release [64-67] and an increase in dopamine neuron firing [38, 39, 54]. In addition, lower GABAergic neural activity leads to a reduction in PV expression [68, 69] and lower PV expression has been correlated with a reduction in coordinated neuronal activity during task performance in rodents [70]. Specifically, PV may modulate GABA transmitter release by acting as an antifacilitation factor [71], where at lower PV concentrations, $\mathrm{PV}$ is acting as a buffer and at higher concentrations the free form of PV may become functionally relevant to have an effect on synaptic dynamics [72-74]. Our findings that ketamine's effects can be reduced by activating PV interneurons and inhibiting midbrain dopamine neurons is consistent with this model. However, it remains possible that ketamine has actions on other neuronal populations that contribute to its effects on striatal dopamine synthesis capacity. Given the evidence of lower PV levels in the frontal cortex and hippocampus in schizophrenia [22-25] and that acute and chronic ketamine administration leads to lower PV levels in the frontal cortex and hippocampus [16, 17, 26-29], we targeted both regions in our chemogenetics experiment. However, a limitation of targeting both regions is that we are not able to distinguish the relative contribution of each region to the effects we observe. Future work targeting each region separately would be useful to determine this. In addition, we investigated the effect of ketamine on PV-positive GABAergic interneurons because this subtype has been specifically implicated in schizophrenia pathophysiology [16, 17]. Notwithstanding this, alterations in other interneurons, particularly somatostatin-positive interneurons, have also been associated with schizophrenia [75]. However, we did not see expression changes in cholecystokinin $(p>0.05)$, nitric oxide synthase $1(p>0.05)$ or somatostatin $(p>0.05)$ in our RNA seq data, suggesting that ketamine does not have major effects on these interneurons in the PLc, although we cannot exclude effects in other brain regions. In contrast, our RNA seq data revealed a significant increase in the expression of VIPR2 in the PLc. This extends a previous finding showing this following acute ketamine administration [76], to indicate that VIPR2 expression is also increased after sub-chronic ketamine administration. VIPR2 is expressed in somatostatinpositive interneurons and increases excitability of these interneurons [76]. This finding highlights that other GABAergic interneurons may be affected by sub-chronic ketamine treatment and the need for further work to determine if expression changes in these interneurons, or others that we were not able to measure such as calretinin positive interneurons, contribute to ketamine's effects on dopamine regulation and behaviour.

Moreover, there is evidence of direct glutamatergic projections from the PLc and other frontal regions to the substantia nigra/VTA that activate dopamine neurons and increase locomotor behaviour in an NMDAR dependent manner [77, 78]. The PLc also projects to the lateral habenula $[79,80]$, which is another major source of glutamatergic projections to the rostromedial tegmental nucleus [81]. In addition, both the PLc and the vSub activate neurons in the amygdala and related regions including the bed 
nucleus of stria terminalis, which project to and may activate VTA dopamine neurons [82, 83]. Glutamatergic projections from the vSub to the nucleus accumbens also activate midbrain dopamine neurons in an NMDAR dependent manner through a pathway involving the ventral pallidum [84]. Furthermore, glutamatergic projections from the pedunculopontine tegmentum to the VTA also activate dopamine neurons $[85,86]$. Thus, our findings could be mediated by direct projections from the PLc to midbrain dopamine neurons and/or one or more indirect pathways. Whilst this was outside the translational aims of our study, further work is required to test whether pyramidal neuron activity is altered in our ketamine model and to characterise the circuit linking cortical and hippocampal PV interneurons to midbrain dopamine neurons.

Ketamine's action on receptors other than the NMDAR, could also contribute to the observed effects [87]. Evidence suggests that ketamine's antidepressant effects could be independent from NMDA receptors expressed in PV interneurons [87] and that deletion of dopamine $\mathrm{D}_{2}$ receptors from PV interneurons induces hyperlocomotion [88]. In addition, recent findings indicate that activation of dopamine $D_{1}$ receptors on pyramidal cells in the prefrontal cortex and/or the action of a metabolite of ketamine on $\alpha$-amino-3-hydroxy-5-methyl-4-isoxazolepropionic acid (AMPA) receptors might contribute to its long-lasting antidepressant effects $[89,90]$. However, ketamine's affinities at other receptors (range of Ki values $=19-131 \mu \mathrm{M}$ ) are considerably lower than its affinity for the NMDAR, and it is not clear if ketamine exhibits significant dopamine receptor occupancy in vivo at behaviourally relevant doses [91, 92]. We suggest that the effects of ketamine in our model likely involve NMDAR blockade, but a contribution from binding to other receptors cannot be excluded.

Ketamine has a short half-life (13 min) in mice [93] and brain levels of its main metabolite $(2 \mathrm{R}, 6 \mathrm{R})$-hydroxynorketamine (HNK), are not detectable $4 \mathrm{~h}$ post administration in mice [90, 94, 95]. Our PET and RNASeq measures were acquired $\sim 48 \mathrm{~h}$ following the last ketamine treatment. Thus, it is unlikely that the observed effects are a consequence of direct ketamine or HNK action. Previous studies have shown that ketamine induces a release of BDNF to increase synaptogenesis [95] and elevates MAPK signalling $[96,97]$. This could present a potential mechanism by which ketamine contributes to the sustained effects observed in our model.

Interestingly, whilst $\mathrm{CNO}$ significantly reduced locomotor activity compared with baseline, it had no effect on dopamine synthesis capacity. It should be noted that locomotor activity was measured shortly after CNO administration whilst dopamine synthesis capacity was measured 2 days following $\mathrm{CNO}$ administration. Electrophysiology recordings show that dopamine neurons recover quickly upon washout of CNO from solution [40]. Thus, our findings indicate that $\mathrm{CNO}$ does not induce lasting changes in dopamine synthesis capacity, but is able to block the effects of ketamine on dopamine synthesis capacity.

A strength of our study is that it utilised a PET imaging approach that parallels the technique used in human studies $[6,30,33]$, supporting the translational relevance of the findings. One consideration for chemogenetic approaches is the cell-type and regional specificity of expression. Injection of viral constructs in wild-type mice revealed no detectable expression (Supplementary Fig. 5), and CNO administration in transgenic mice expressing a control construct had no effect on the ketamine-induced increase in dopamine synthesis capacity and locomotor activity. Limitations include that we did not measure other aspects of dopamine function or investigate other brain regions. Moreover, we did not test whether the effects of SEP-856 are predominately mediated via TAAR1 agonism and its action on dopamine neuron firing, or also driven by the compound's activities at other receptors [20]. To date SEP856 has been tested for binding and/or functional activity against multiple panels of known molecular targets (ion channels, G-protein-coupled receptors and enzymes), demonstrating a range of activities at several receptors [20]. While the most notable functional activity is full agonism at TAAR1 (EC50 of $0.14 \mu \mathrm{M}$ ), SEP-856 also exhibits binding and agonist activity at the $5-\mathrm{HT}_{1 \mathrm{~A}}$ receptor (5$\left.\mathrm{HT}_{1 \mathrm{~A}} \mathrm{R}\right)$, although with lower potency than for TAAR1 (EC50 of $2.3 \mu \mathrm{M})$ [20]. Notwithstanding this, attenuation of PCP induced hyperlocomotion by SEP-856 is partially blocked by a $5 \mathrm{HT}_{1 \mathrm{~A}} \mathrm{R}$ antagonist [20], suggesting that its effects in our ketamine model could be partly mediated by $5 \mathrm{HT}_{1 \mathrm{~A}} \mathrm{R}$. Following our translational work, future pharmacology studies will help elucidate the molecular and circuit mechanisms by which SEP-856 attenuates the ketamine-induced increase in striatal dopamine synthesis capacity.

\section{Implications for understanding the pathophysiology of schizophrenia and the antidepressant mode of action of ketamine}

PET imaging studies have repeatedly shown elevated dopamine synthesis and release capacity in schizophrenia (e.g. [7, 98] and see review [6]), and suggested that this is linked to the development of psychosis [99, 100] and changes in cortical glutamate levels [101]. Moreover, cortical and hippocampal PV interneuron density and PV protein levels have been shown to be reduced in schizophrenia (see meta-analysis [25] and [102]). Ketamine induces psychotic symptoms in healthy volunteers, and 
worsens symptoms in patients with schizophrenia [14, 15]. Our findings indicate that ketamine's effect on dopamine synthesis capacity involves PV-positive interneurons in regions implicated in schizophrenia. These findings suggest that inhibition of midbrain dopamine neurons and/or activation of cortical PV interneurons could represent novel therapeutic strategies for schizophrenia. Furthermore, our finding that SEP-856, a novel TAAR $1 / 5 \mathrm{HT}_{1 \mathrm{~A}}$ agonist, reduces sub-chronic ketamine-induced elevation in striatal dopamine synthesis capacity provides a proof-of-concept for pharmacological attenuation of presynaptic dopamine dysfunction. The reduction in PV levels following ketamine in our model was large (Hedge's $g=-2.29$ ), which compares to a moderate-large effect size (Hedge's $g=-0.61$ ) reduction in PV-positive neuron immunoreactivity reported post-mortem in schizophrenia [102]. Thus, our ketamine model likely induces more marked effects on PV than are typically seen in schizophrenia.

Lastly, our data may also have implications for understanding ketamine's antidepressant actions and its abuse potential. There is some evidence that major depression is associated with blunted dopaminergic function, including reduced levels of dopamine metabolites post-mortem and reduced dopamine synthesis capacity $[103,104]$. Moreover, animal models mimicking the neurochemical changes seen in depression exhibit reduced dopamine neuron population activity [38]. Our findings that sub-chronic ketamine administration elevates striatal dopamine synthesis capacity, which persists for several days post dosing, suggest that this could contribute to ketamine's antidepressant actions [48]. The majority of pre-clinical studies investigating the antidepressant effects of ketamine used a $10 \mathrm{mg} / \mathrm{kg}$ dose of ketamine, but doses as high as $50 \mathrm{mg} / \mathrm{kg}$ have also been used to show antidepressant-like effects [105-110]. In human studies the optimal therapeutic dose for ketamine is debated, with $0.5 \mathrm{mg} / \mathrm{kg}$ having dissociative, psychotomimetic and antidepressant effects [111, 112], whilst $0.2 \mathrm{mg} / \mathrm{kg}$ is generally considered sub-therapeutic, although one study reported positive therapeutic effects with $0.1 \mathrm{mg} / \mathrm{kg}$ $[14,111,113]$. Thus, it would be useful to determine if lower ketamine doses than we used also result in persistent increases in dopamine synthesis capacity. It should also be noted that other mechanisms, such as augmenting ERK1/MAPK signalling and AMPA activity, are also implicated ketamine's antidepressant actions [114]. In line with this and previous findings, we show that sub-chronic ketamine administration leads to the increase in the expression of genes involved in the pathway downstream of BDNF signalling, such as upregulation of MAPK3 suggesting this could contribute to ketamine's antidepressant effects [96, 97].

\section{Conclusion}

We demonstrate that sub-chronic ketamine leads to an increase in striatal dopamine synthesis capacity in the mouse, resembling the dopaminergic alteration seen in patients with schizophrenia. Our data suggest that ketamine's effects on dopamine synthesis capacity are mediated by inhibition of PV interneurons in the cortex and vSub as well as activation of midbrain dopamine neurons, and that these alterations can be attenuated by a TAAR1 agonist with $5-\mathrm{HT}_{1 \mathrm{~A}}$ activity.

Acknowledgements We are grateful to Darran Hardy, Paulius Viskaitis, Maria Paiva-Pessoa, Sac-Pham Tang, Sharon Ashworth, Bilbinder Bhachu, Anna Pacelli, Stuart McCluskey, Ivan Andrew and the radiochemistry and biology teams at Invicro and to the CBS staff members at Imperial College London and the genomics facility and bioinformatics facility at the London Institute of Medical Sciences. The dopamine transporter $(D A T):: C r e$ mouse line was kindly gifted by Professor Francois Tronche (University of Pierre and Marie Curie, Paris). The study was funded by the Medical Research Council (MRC) UK grant (no. MC-A656-5QD30), Maudsley Charity (no. 666), Brain and Behaviour Research Foundation, and Wellcome Trust (no. 094849/Z/10/Z) grants to Professor Howes and the National Institute for Health Research (NIHR) Biomedical Research Centre at South London and Maudsley NHS Foundation Trust and King's College London, and the MRC UK grant to DJW (no. MC-A654-5QB40) and MAU (no. MC-A654-5QB70). Sunovion discovered SEP-363856 in collaboration with PsychoGenics based in part on a mechanismindependent approach using the in vivo phenotypic SmartCube ${ }^{\varpi}$ platform and associated artificial intelligence algorithms.

Author contributions MK, ODH, MAU, DJW and EEI contributed to study design. MK, EEI, DRB, SN, LAW, MAS, JG, EJP, KT, MV, SK, ND, SCH, MAU, DJW and ODH contributed to data collection or interpretation. MK coordinated all experiments. MK, DJW and ODH. wrote the original draft. All the authors critically revised the article. All authors approved the last version. Supervision was provided by MAU, DJW and ODH.

\section{Compliance with ethical standards}

Conflict of interest MK conducted research funded by Medical Research Council. MV is supported by the National Institute for Health Research (NIHR) Biomedical Research Centre at South London and Maudsley NHS Foundation Trust and King's College London. ODH conducts research funded by the Medical Research Council (UK), the National Institute of Health Research (UK) and the Maudsley Charity. ODH has received investigator-initiated research funding from and/or participated in advisory/speaker meetings organised by Angellini, Eli Lilly, Jansenn, Lundbeck, Lyden-Delta, Mylan, Otsuka, Sunovion and Roche. Neither ODH nor his family have been employed by or have holdings/a financial stake in any biomedical company. ND and $\mathrm{SCH}$ are employees of Sunovion Pharmaceuticals. DB and LW are employees of Invicro. EI, SN, MS, JG, EP, KT, SK, MU and DW have no financial interests to disclose.

Publisher's note Springer Nature remains neutral with regard to jurisdictional claims in published maps and institutional affiliations. 
Open Access This article is licensed under a Creative Commons Attribution 4.0 International License, which permits use, sharing, adaptation, distribution and reproduction in any medium or format, as long as you give appropriate credit to the original author(s) and the source, provide a link to the Creative Commons license, and indicate if changes were made. The images or other third party material in this article are included in the article's Creative Commons license, unless indicated otherwise in a credit line to the material. If material is not included in the article's Creative Commons license and your intended use is not permitted by statutory regulation or exceeds the permitted use, you will need to obtain permission directly from the copyright holder. To view a copy of this license, visit http://creativecommons. org/licenses/by/4.0/.

\section{References}

1. Whiteford HA, Degenhardt L, Rehm J, Baxter AJ, Ferrari AJ, Erskine HE, et al. Global burden of disease attributable to mental and substance use disorders: findings from the Global Burden of Disease Study 2010. Lancet. 2013;382:1575-86.

2. Howes O, McCutcheon R, Stone J. Glutamate and dopamine in schizophrenia: an update for the 21 st century. J Psychopharmacol. 2015;29:97-115.

3. Lodge DJ, Grace AA. Hippocampal dysregulation of dopamine system function and the pathophysiology of schizophrenia. Trends Pharmacol Sci. 2011;32:507-13.

4. Weinstein JJ, Chohan MO, Slifstein M, Kegeles LS, Moore H, Abi-Dargham A. Pathway-specific dopamine abnormalities in schizophrenia. Biol Psychiatry. 2017;81:31-42.

5. Uchida H, Takeuchi H, Graff-Guerrero A, Suzuki T, Watanabe K, Mamo DC. Dopamine D2 receptor occupancy and clinical effects: a systematic review and pooled analysis. J Clin Psychopharmacol. 2011;31:497-502.

6. Howes OD, Kambeitz J, Kim E, Stahl D, Slifstein M, AbiDargham A, et al. The nature of dopamine dysfunction in schizophrenia and what this means for treatment. Arch Gen Psychiatry. 2012;69:776-86.

7. Reith J, Benkelfat C, Sherwin A, Yasuhara Y, Kuwabara H, Andermann F, et al. Elevated dopa decarboxylase activity in living brain of patients with psychosis. Proc Natl Acad Sci USA. 1994;91:11651-4.

8. Hietala J, Syvalahti E, Vuorio K, Rakkolainen V, Bergman J, Haaparanta M, et al. Presynaptic dopamine function in striatum of neuroleptic-naive schizophrenic patients. Lancet. 1995;346:1130-1.

9. Meyer-Lindenberg A, Miletich RS, Kohn PD, Esposito G, Carson RE, Quarantelli M, et al. Reduced prefrontal activity predicts exaggerated striatal dopaminergic function in schizophrenia. Nat Neurosci. 2002;5:267-71.

10. Howes O, Bose S, Turkheimer F, Valli I, Egerton A, Stahl D, et al. Progressive increase in striatal dopamine synthesis capacity as patients develop psychosis: a PET study. Mol Psychiatry. 2011;16:885-6.

11. Jauhar S, Nour MM, Veronese M, Rogdaki M, Bonoldi I, Azis $\mathrm{M}$, et al. A test of the transdiagnostic dopamine hypothesis of psychosis using positron emission tomographic imaging in bipolar affective disorder and schizophrenia. JAMA Psychiatry. 2017;74:1206-13.

12. Abi-Dargham A, Laruelle M. Mechanisms of action of second generation antipsychotic drugs in schizophrenia: insights from brain imaging studies. Eur Psychiatry. 2005;20:15-27.

13. Howes OD, McCutcheon R, Owen MJ, Murray RM. The role of genes, stress, and dopamine in the development of schizophrenia. Biol Psychiatry. 2017;81:9-20.

14. Krystal JH, Karper LP, Seibyl JP, Freeman GK, Delaney R, Bremner JD, et al. Subanesthetic effects of the noncompetitive
NMDA antagonist, ketamine, in humans. Psychotomimetic, perceptual, cognitive, and neuroendocrine responses. Arch Gen Psychiatry. 1994;51:199-214.

15. Lahti AC, Koffel B, LaPorte D, Tamminga CA. Subanesthetic doses of ketamine stimulate psychosis in schizophrenia. Neuropsychopharmacology. 1995;13:9-19.

16. Benes FM, McSparren J, Bird ED, SanGiovanni JP, Vincent SL. Deficits in small interneurons in prefrontal and cingulate cortices of schizophrenic and schizoaffective patients. Arch Gen Psychiatry. 1991;48:996-1001.

17. Zhang ZJ, Reynolds GP. A selective decrease in the relative density of parvalbumin-immunoreactive neurons in the hippocampus in schizophrenia. Schizophr Res. 2002;55:1-10.

18. Dwir D, Giangreco B, Xin L, Tenenbaum L, Cabungcal JH, Steullet $\mathrm{P}$, et al. MMP9/RAGE pathway overactivation mediates redox dysregulation and neuroinflammation, leading to inhibitory/excitatory imbalance: a reverse translation study in schizophrenia patients. Mol Psychiatry. 2019. https://doi.org/10.1038/ s41380-019-0393-5.

19. Grace AA. Dysregulation of the dopamine system in the pathophysiology of schizophrenia and depression. Nat Rev Neurosci. 2016;17:524-32.

20. Dedic N, Jones PG, Hopkins SC, Lew R, Shao L, Campbell JE, et al. SEP-363856, a novel psychotropic agent with a unique, non-D2 receptor mechanism of action. J Pharmacol Exp Ther. 2019;371:1-14.

21. McNally JM, McCarley RW, Brown RE. Chronic ketamine reduces the peak frequency of gamma oscillations in mouse prefrontal cortex ex vivo. Front Psychiatry. 2013;4:106.

22. Perry TL, Kish SJ, Buchanan J, Hansen S. Gammaaminobutyric-acid deficiency in brain of schizophrenic patients. Lancet. 1979;1:237-9.

23. Benes FM, Lim B, Matzilevich D, Walsh JP, Subburaju S, Minns M. Regulation of the GABA cell phenotype in hippocampus of schizophrenics and bipolars. Proc Natl Acad Sci USA. 2007;104:10164-9.

24. Lisman JE, Coyle JT, Green RW, Javitt DC, Benes FM, Heckers $\mathrm{S}$, et al. Circuit-based framework for understanding neurotransmitter and risk gene interactions in schizophrenia. Trends Neurosci. 2008;31:234-42.

25. Kaar SJ, Angelescu I, Marques TR, Howes OD. Pre-frontal parvalbumin interneurons in schizophrenia: a meta-analysis of post-mortem studies. J Neural Transm. 2019;126:1637-51.

26. Zhou X, Wang Y, Zhang C, Wang M, Zhang M, Yu L, et al. The role of dopaminergic VTA neurons in general anesthesia. PloS ONE. 2015;10:e0138187.

27. Keilhoff G, Becker A, Grecksch G, Wolf G, Bernstein HG. Repeated application of ketamine to rats induces changes in the hippocampal expression of parvalbumin, neuronal nitric oxide synthase and cFOS similar to those found in human schizophrenia. Neuroscience. 2004;126:591-8.

28. Zhang Y, Behrens MM, Lisman JE. Prolonged exposure to NMDAR antagonist suppresses inhibitory synaptic transmission in prefrontal cortex. J Neurophysiol. 2008;100:959-65.

29. Wang N, Zhang GF, Liu XY, Sun HL, Wang XM, Qiu LL, et al. Downregulation of neuregulin 1-ErbB4 signaling in parvalbumin interneurons in the rat brain may contribute to the antidepressant properties of ketamine. J Mol Neurosci. 2014;54:211-8.

30. Walker MD, Dinelle K, Kornelsen R, McCormick S, Mah C, Holden JE, et al. In-vivo measurement of LDOPA uptake, dopamine reserve and turnover in the rat brain using $\left[{ }^{18} \mathrm{~F}\right]$ FDOPA PET. J Cereb Blood Flow Metab. 2013;33:59-66.

31. Bonsall DR, Kokkinou M, Veronese M, Coello C, Wells LA, Howes OD. Single cocaine exposure does not alter striatal presynaptic dopamine function in mice: an $\left[{ }^{18} \mathrm{~F}\right]-$ FDOPA PET study. J Neurochem. 2017;143:551-60. 
32. Holden JE, Doudet D, Endres CJ, Chan GL, Morrison KS, Vingerhoets FJ, et al. Graphical analysis of 6-fluoro-L-dopa trapping: effect of inhibition of catechol-O-methyltransferase. J Nucl Med. 1997;38:1568-74.

33. Cumming P, Kuwabara H, Ase A, Gjedde A. Regulation of DOPA decarboxylase activity in brain of living rat. J Neurochem. 1995;65:1381-90.

34. Egerton A, Demjaha A, McGuire P, Mehta MA, Howes OD. The test-retest reliability of 18F-DOPA PET in assessing striatal and extrastriatal presynaptic dopaminergic function. Neuroimage. 2010;50:524-31.

35. Kim D, Pertea G, Trapnell C, Pimentel H, Kelley R, Salzberg SL. TopHat2: accurate alignment of transcriptomes in the presence of insertions, deletions and gene fusions. Genome Biol. 2013;14:R36.

36. O'Tuathaigh CM, Waddington JL. Closing the translational gap between mutant mouse models and the clinical reality of psychotic illness. Neurosci Biobehav Rev. 2015;58:19-35.

37. French ED, Ceci A. Non-competitive N-methyl-D-aspartate antagonists are potent activators of ventral tegmental A10 dopamine neurons. Neurosci Lett. 1990;119:159-62.

38. Belujon P, Grace AA. Restoring mood balance in depression: ketamine reverses deficit in dopamine-dependent synaptic plasticity. Biol Psychiatry. 2014;76:927-36.

39. Witkin JM, Monn JA, Schoepp DD, Li X, Overshiner C, Mitchell SN, et al. The rapidly acting antidepressant ketamine and the mGlu2/3 receptor antagonist LY341495 rapidly engage dopaminergic mood circuits. J Pharmacol Exp Ther. 2016; 358:71-82.

40. Sandhu EC, Fernando ABP, Irvine EE, Tossell K, Kokkinou M, Glegola J, et al. Phasic stimulation of midbrain dopamine neuron activity reduces salt consumption. eNeuro. 2018;5.

41. Gomez JL, Bonaventura J, Lesniak W, Mathews WB, Sysa-Shah $\mathrm{P}$, Rodriguez LA, et al. Chemogenetics revealed: DREADD occupancy and activation via converted clozapine. Science. 2017;357:503-7.

42. Zhou Z, Zhang G, Li X, Liu X, Wang N, Qiu L, et al. Loss of phenotype of parvalbumin interneurons in rat prefrontal cortex is involved in antidepressant- and propsychotic-like behaviors following acute and repeated ketamine administration. Mol Neurobiol. 2015;51:808-19.

43. Gideons ES, Kavalali ET, Monteggia LM. Mechanisms underlying differential effectiveness of memantine and ketamine in rapid antidepressant responses. Proc Natl Acad Sci USA. 2014;111:8649-54.

44. Edwards AC, Bacanu SA, Bigdeli TB, Moscati A, Kendler KS. Evaluating the dopamine hypothesis of schizophrenia in a largescale genome-wide association study. Schizophr Res. 2016;176: 136-40.

45. Chung DW, Fish KN, Lewis DA. Pathological basis for deficient excitatory drive to cortical parvalbumin interneurons in schizophrenia. Am J Psychiatry. 2016;173:1131-9.

46. Xie Z, Miller GM. Trace amine-associated receptor 1 as a monoaminergic modulator in brain. Biochemical Pharmacol. 2009;78:1095-104.

47. Lindemann L, Meyer CA, Jeanneau K, Bradaia A, Ozmen L, Bluethmann $\mathrm{H}$, et al. Trace amine-associated receptor 1 modulates dopaminergic activity. J Pharmacol Exp Ther. 2008;324:948-56.

48. Revel FG, Moreau JL, Gainetdinov RR, Bradaia A, Sotnikova TD, Mory R, et al. TAAR1 activation modulates monoaminergic neurotransmission, preventing hyperdopaminergic and hypoglutamatergic activity. Proc Natl Acad Sci USA. 2011;108: 8485-90.

49. Leo D, Mus L, Espinoza S, Hoener MC, Sotnikova TD, Gainetdinov RR. Taar1-mediated modulation of presynaptic dopaminergic neurotransmission: role of D2 dopamine autoreceptors. Neuropharmacology. 2014;81:283-91.

50. Kokkinou M, Ashok AH, Howes OD. The effects of ketamine on dopaminergic function: meta-analysis and review of the implications for neuropsychiatric disorders. Mol Psychiatry. 2018;23: 59-69.

51. Verma A, Moghaddam B. NMDA receptor antagonists impair prefrontal cortex function as assessed via spatial delayed alternation performance in rats: modulation by dopamine. J Neurosci. 1996;16:373-9.

52. Usun Y, Eybrard S, Meyer F, Louilot A. Ketamine increases striatal dopamine release and hyperlocomotion in adult rats after postnatal functional blockade of the prefrontal cortex. Behav Brain Res. 2013;256:229-37.

53. Lai CC, Lee LJ, Yin HS. Combinational effects of ketamine and amphetamine on behaviors and neurotransmitter systems of mice. Neurotoxicology. 2013;37:136-43.

54. El Iskandrani KS, Oosterhof CA, El Mansari M, Blier P. Impact of subanesthetic doses of ketamine on AMPA-mediated responses in rats: an in vivo electrophysiological study on monoaminergic and glutamatergic neurons. J Psychopharmacol. 2015;29:792-801.

55. Nishimura M, Sato K, Okada T, Yoshiya I, Schloss P, Shimada $\mathrm{S}$, et al. Ketamine inhibits monoamine transporters expressed in human embryonic kidney 293 cells. Anesthesiology. 1998;88: 768-74.

56. Seeman P, Ko F, Tallerico T. Dopamine receptor contribution to the action of PCP, LSD and ketamine psychotomimetics. Mol Psychiatry. 2005;10:877-83.

57. Dingledine R, Borges K, Bowie D, Traynelis SF. The glutamate receptor ion channels. Pharmacol Rev. 1999;51:7-61.

58. Javitt DC. Glutamatergic theories of schizophrenia. Isr J Psychiatry Relat Sci. 2010;47:4-16.

59. Coyle JT. NMDA receptor and schizophrenia: a brief history. Schizophrenia Bull. 2012;38:920-6.

60. Coyle JT. Glutamate and schizophrenia: beyond the dopamine hypothesis. Cell Mol Neurobiol. 2006;26:365-84.

61. Javitt DC. Glutamate and schizophrenia: phencyclidine, Nmethyl-D-aspartate receptors, and dopamine-glutamate interactions. Int Rev Neurobiol. 2007;78:69-108.

62. Javitt DC, Zukin SR, Heresco-Levy U, Umbricht D. Has an angel shown the way? Etiological and therapeutic implications of the PCP/NMDA model of schizophrenia. Schizophr Bull. 2012;38:958-66.

63. Moghaddam B, Adams B, Verma A, Daly D. Activation of glutamatergic neurotransmission by ketamine: a novel step in the pathway from NMDA receptor blockade to dopaminergic and cognitive disruptions associated with the prefrontal cortex. J Neurosci. 1997;17:2921-7.

64. Rowland LM, Bustillo JR, Mullins PG, Jung RE, Lenroot R, Landgraf $\mathrm{E}$, et al. Effects of ketamine on anterior cingulate glutamate metabolism in healthy humans: a 4-T proton MRS study. Am J Psychiatry. 2005;162:394-6.

65. Stone JM, Dietrich C, Edden R, Mehta MA, De Simoni S, Reed LJ, et al. Ketamine effects on brain GABA and glutamate levels with 1H-MRS: relationship to ketamine-induced psychopathology. Mol Psychiatry. 2012;17:664-5.

66. Kim SY, Lee H, Kim HJ, Bang E, Lee SH, Lee DW, et al. In vivo and ex vivo evidence for ketamine-induced hyperglutamatergic activity in the cerebral cortex of the rat: potential relevance to schizophrenia. NMR Biomed. 2011;24:1235-42.

67. Abdallah CG, Sanacora G, Duman RS, Krystal JH. Ketamine and rapid-acting antidepressants: a window into a new neurobiology for mood disorder therapeutics. Annu Rev Med. 2015;66:509-23. 
68. Patz S, Grabert J, Gorba T, Wirth MJ, Wahle P. Parvalbumin expression in visual cortical interneurons depends on neuronal activity and TrkB ligands during an Early period of postnatal development. Cereb Cortex. 2004;14:342-51.

69. Jiang M, Swann JW. A role for L-type calcium channels in the maturation of parvalbumin-containing hippocampal interneurons. Neuroscience. 2005;135:839-50.

70. Lodge DJ, Behrens MM, Grace AA. A loss of parvalbumincontaining interneurons is associated with diminished oscillatory activity in an animal model of schizophrenia. J Neurosci. 2009;29:2344-54.

71. Eggermann E, Jonas P. How the 'slow' $\mathrm{Ca}(2+)$ buffer parvalbumin affects transmitter release in nanodomain-coupling regimes. Nat Neurosci. 2011;15:20-2.

72. Schwaller B, Meyer M, Schiffmann S. 'New' functions for 'old' proteins: the role of the calcium-binding proteins calbindin D$28 \mathrm{k}$, calretinin and parvalbumin, in cerebellar physiology. Studies with knockout mice. Cerebellum. 2002;1:241-58.

73. Donato F, Rompani SB, Caroni P. Parvalbumin-expressing basket-cell network plasticity induced by experience regulates adult learning. Nature. 2013;504:272-6.

74. Hu H, Gan J, Jonas P. Interneurons. Fast-spiking, parvalbumin (+) GABAergic interneurons: from cellular design to microcircuit function. Science. 2014;345:1255263.

75. Morris HM, Hashimoto T, Lewis DA. Alterations in somatostatin mRNA expression in the dorsolateral prefrontal cortex of subjects with schizophrenia or schizoaffective disorder. Cereb Cortex. 2008;18:1575-87.

76. Miller O, Grabole N, Wells I, Hall BJ. Genome-wide translating mRNA analysis following ketamine reveals novel targets for antidepressant treatment. bioRxiv preprint. 2018. https://doi.org/ $10.1101 / 254904$.

77. Carr DB, Sesack SR. Projections from the rat prefrontal cortex to the ventral tegmental area: target specificity in the synaptic associations with mesoaccumbens and mesocortical neurons. $\mathrm{J}$ Neurosci. 2000;20:3864-73.

78. Geisler S, Derst C, Veh RW, Zahm DS. Glutamatergic afferents of the ventral tegmental area in the rat. $\mathrm{J}$ Neurosci. 2007;27:5730-43.

79. Vertes RP. Interactions among the medial prefrontal cortex, hippocampus and midline thalamus in emotional and cognitive processing in the rat. Neuroscience. 2006;142:1-20.

80. Kim U, Lee T. Topography of descending projections from anterior insular and medial prefrontal regions to the lateral habenula of the epithalamus in the rat. Eur $\mathbf{J}$ Neurosci. 2012;35:1253-69.

81. Jhou TC, Fields HL, Baxter MG, Saper CB, Holland PC. The rostromedial tegmental nucleus (RMTg), a GABAergic afferent to midbrain dopamine neurons, encodes aversive stimuli and inhibits motor responses. Neuron. 2009;61:786-800.

82. Fudge JL, Kelly EA, Pal R, Bedont JL, Park L, Ho B. Beyond the Classic VTA: Extended Amygdala Projections to DA-Striatal Paths in the Primate. Neuropsychopharmacology. 2017;42: 1563-76.

83. Kim SY, Adhikari A, Lee SY, Marshel JH, Kim CK, Mallory $\mathrm{CS}$, et al. Diverging neural pathways assemble a behavioural state from separable features in anxiety. Nature. 2013;496: 219-23.

84. Floresco SB, Todd CL, Grace AA. Glutamatergic afferents from the hippocampus to the nucleus accumbens regulate activity of ventral tegmental area dopamine neurons. J Neurosci. 2001;21: 4915-22.

85. Floresco SB, Grace AA. Gating of hippocampal-evoked activity in prefrontal cortical neurons by inputs from the mediodorsal thalamus and ventral tegmental area. J Neurosci. 2003;23: 3930-43.
86. Lodge DJ, Grace AA. The hippocampus modulates dopamine neuron responsivity by regulating the intensity of phasic neuron activation. Neuropsychopharmacology. 2006;31:1356-61.

87. Pozzi L, Pollak Dorocic I, Wang X, Carlen M, Meletis K. Mice lacking NMDA receptors in parvalbumin neurons display normal depression-related behavior and response to antidepressant action of NMDAR antagonists. PloS ONE. 2014;9:e83879.

88. Tomasella E, Bechelli L, Ogando MB, Mininni C, Di Guilmi MN, De Fino F, et al. Deletion of dopamine D2 receptors from parvalbumin interneurons in mouse causes schizophrenia-like phenotypes. Proc Natl Acad Sci USA 2018;115:3476-81.

89. Hare BD, Shinohara R, Liu RJ, Pothula S, DiLeone RJ, Duman RS. Optogenetic stimulation of medial prefrontal cortex Drd1 neurons produces rapid and long-lasting antidepressant effects. Nat Commun. 2019;10:223.

90. Zanos P, Moaddel R, Morris PJ, Georgiou P, Fischell J, Elmer GI, et al. NMDAR inhibition-independent antidepressant actions of ketamine metabolites. Nature. 2016;533:481-6.

91. Can A, Zanos P. Effects of ketamine and ketamine metabolites on evoked striatal dopamine release, dopamine receptors, and monoamine transporters. J Pharmacol Exp Ther. 2016;359: 159-70.

92. Aalto S, Hirvonen J, Kajander J, Scheinin H, Nagren K, Vilkman $\mathrm{H}$, et al. Ketamine does not decrease striatal dopamine D2 receptor binding in man. Psychopharmacology. 2002;164:401-6.

93. Maxwell CR, Ehrlichman RS, Liang Y, Trief D, Kanes SJ, Karp $\mathrm{J}$, et al. Ketamine produces lasting disruptions in encoding of sensory stimuli. J Pharmacol Exp Ther. 2006;316:315-24.

94. Aleksandrova LR, Wang YT, Phillips AG. Hydroxynorketamine: implications for the NMDA receptor hypothesis of ketamine's antidepressant action. Chronic Stress. 2017;1.

95. Abdallah CG. What's the buzz about hydroxynorketamine? Is it the history, the story, the debate, or the promise? Biol Psychiatry. 2017;81:e61-3.

96. Talebian A, Robinson-Brookes K, Meakin SO. TrkB regulates N-Methyl-D-Aspartate receptor signaling by uncoupling and recruiting the brain-specific guanine nucleotide exchange factor, RasGrf1. J Mol Neurosci. 2019;67:97-110.

97. Reus GZ, Vieira FG, Abelaira HM, Michels M, Tomaz DB, dos Santos MA, et al. MAPK signaling correlates with the antidepressant effects of ketamine. J Psychiatr Res. 2014;55:15-21.

98. Kumakura Y, Cumming P, Vernaleken I, Buchholz HG, Siessmeier T, Heinz A, et al. Elevated $\left[{ }^{18} \mathrm{~F}\right]$ fluorodopamine turnover in brain of patients with schizophrenia: an $\left[{ }^{18} \mathrm{~F}\right]$ fluorodopa/ positron emission tomography study. J Neurosci. 2007;27: 8080-7.

99. Howes OD, Bose SK, Turkheimer F, Valli I, Egerton A, Valmaggia LR, et al. Dopamine synthesis capacity before onset of psychosis: a prospective $\left[{ }^{18} \mathrm{~F}\right]-\mathrm{DOPA}$ PET imaging study. Am J Psychiatry. 2011;168:1311-7.

100. Egerton A, Chaddock CA, Winton-Brown TT, Bloomfield MA, Bhattacharyya S, Allen $\mathrm{P}$, et al. Presynaptic striatal dopamine dysfunction in people at ultra-high risk for psychosis: findings in a second cohort. Biol Psychiatry. 2013; 74:106-12.

101. Jauhar S, McCutcheon R, Borgan F, Veronese M, Nour M, Pepper F, et al. The relationship between cortical glutamate and striatal dopamine in first-episode psychosis: a cross-sectional multimodal PET and magnetic resonance spectroscopy imaging study. Lancet Psychiatry. 2018;5:816-23.

102. Enwright JF, Sanapala S, Foglio A, Berry R, Fish KN, Lewis DA. Reduced labeling of parvalbumin neurons and perineuronal nets in the dorsolateral prefrontal cortex of subjects with schizophrenia. Neuropsychopharmacology. 2016;41:2206-14.

103. Martinot M, Bragulat V, Artiges E, Dolle F, Hinnen F, Jouvent $\mathrm{R}$, et al. Decreased presynaptic dopamine function in the left 
caudate of depressed patients with affective flattening and psychomotor retardation. Am J Psychiatry. 2001;158:314-6.

104. Bowden C, Cheetham SC, Lowther S, Katona CL, Crompton MR, Horton RW. Reduced dopamine turnover in the basal ganglia of depressed suicides. Brain Res. 1997;769:135-40.

105. Fitzgerald PJ, Yen JY, Watson BO. Stress-sensitive antidepressant-like effects of ketamine in the mouse forced swim test. PLoS One. 2019;14:e0215554.

106. Browne CA, Lucki I. Antidepressant effects of ketamine: mechanisms underlying fast-acting novel antidepressants. Front Pharmacol. 2013;4:161.

107. Koike H, Iijima M, Chaki S. Involvement of the mammalian target of rapamycin signaling in the antidepressant-like effect of group II metabotropic glutamate receptor antagonists. Neuropharmacology. 2011;61:1419-23.

108. Koike H, Iijima M, Chaki S. Involvement of AMPA receptor in both the rapid and sustained antidepressant-like effects of ketamine in animal models of depression. Behav Brain Res. 2011;224:107-11.

109. Cruz SL, Soberanes-Chavez P, Paez-Martinez N, LopezRubalcava C. Toluene has antidepressant-like actions in two animal models used for the screening of antidepressant drugs. Psychopharmacology. 2009;204:279-86.

110. Lindholm JS, Autio H, Vesa L, Antila H, Lindemann L, Hoener $\mathrm{MC}$, et al. The antidepressant-like effects of glutamatergic drugs ketamine and AMPA receptor potentiator LY 451646 are preserved in bdnf $(+) /(-)$ heterozygous null mice. Neuropharmacology. 2012;62:391-7.

111. Fava M, Freeman MP, Flynn M, Judge H, Hoeppner BB, Cusin $\mathrm{C}$, et al. Double-blind, placebo-controlled, dose-ranging trial of intravenous ketamine as adjunctive therapy in treatment-resistant depression (TRD). Mol Psychiatry. 2018. https://doi.org/10. 1038/s41380-018-0256-5.

112. Su TP, Chen MH, Li CT, Lin WC, Hong CJ, Gueorguieva R, et al. Dose-related effects of adjunctive ketamine in Taiwanese patients with treatment-resistant. Depression. 2017;42: 2482-92.

113. Krystal JH, Abdallah CG, Sanacora G, Charney DS, Duman RS. Ketamine: a paradigm shift for depression research and treatment. Neuron. 2019;101:774-8.

114. Zanos P, Gould TD. Mechanisms of ketamine action as an antidepressant. Mol Psychiatry. 2018;23:801-11. 